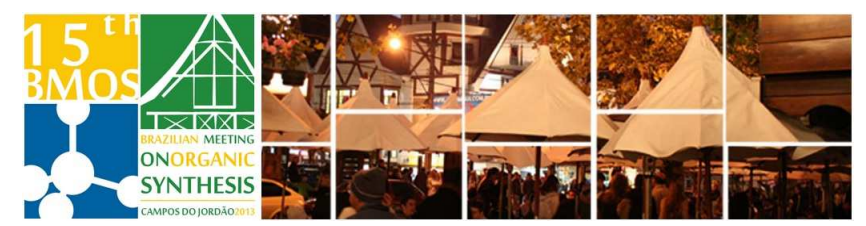

\title{
Asymmetrical Henry reaction using copper (II)/2-oxazoline \\ complex.
}

\author{
Murilo B. M. Mello, Alfredo R. M. Oliveira, ${ }^{*}$ and Ronny R. Ribeiro
}

Universidade Federal do Paraná, Departamento de Química, Centro Politécnico, Jd das Américas, Curitiba, 81.531-991 *armo@ufpr.br

Keywords: 2-oxazoline, nitro aldol, copper catalyst.

\section{INTRODUCTION}

The Henry reaction or nitro aldol reaction is one of the most versatile methods to obtain a new $\mathrm{C}-\mathrm{C}$ bond. The asymmetric version of this reaction has been used to generate a variety of useful building blocks $^{[1]}$ for organic synthesis. The catalytic asymmetric Henry reaction uses chiral ligands as a source of asymmetry and amino alcohols have found applications as catalysts in asymmetric reactions $^{22}$. Among several asymmetric ligands, several 2-oxazolines derivatives have been used as metal ligands in this type of reaction ${ }^{[3-5]}$. In this context, the asymmetrical catalyst copper/2oxazoline chiral derivative was studied using a new class of chiral 2-oxazoline compounds.

\section{RESULTS AND DISCUSSION}

After some optimization studies compounds 1, 3, and 4 were obtained. These 2-oxazoline compounds were mixed with copper (II) acetate and submitted to EPR analysis in frozen ethanol. Scheme 1 outlines the synthesis of 2-oxazoline ether derivatives:

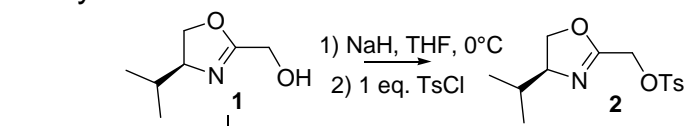

$$
\begin{aligned}
& \text { 1) } \mathrm{NaH}, 0,5 \text { eq. } \mathrm{TsCl} \\
& \mathrm{THF} \text {, reflux }
\end{aligned}
$$

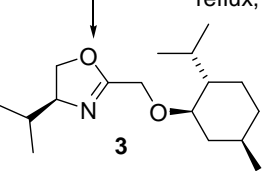

Scheme 1. Synthesis of 2-oxazolines ligands.

Compound 1 shows a $\mathrm{Cu}$ (II) spectrum, characteristic of a tetragonal elongated geometry, additionally modulated by a superhyperfine signal originated from two chemically equivalent nitrogen nuclei. These observations were further confirmed upon spectral simulation. Moreover, the ratio between the hyperfine parallel splitting and the parallel g-factor points to a $2 \mathrm{~N} 2 \mathrm{O}$ coordination scheme. ${ }^{[6]}$ Compound 3 has no signal in EPR analysis, indicating that no complex was formed, while for compound 4 EPR analyses shows a spectrum of two species in equilibrium, with a ratio of $47 \%$ to $53 \%$.

To optimize the Henry reaction, a solvent screening was performed using dichloromethane, water, isopropanol, ethanol and THF. The best solubility result was obtained using ethanol and THF.
The nitro aldol reactions were also performed without any ligand, to verify its influence in the reaction kinetics. In THF without ligand the yield was significantly lower furnishing 15\%. Using ethanol yields $65 \%$ of nitro aldol product. Having selected the best solvent, the asymmetrical Henry reaction was performed using $\mathbf{1}$ as a ligand. The reaction conditions are shown in the Tagble 1 below.

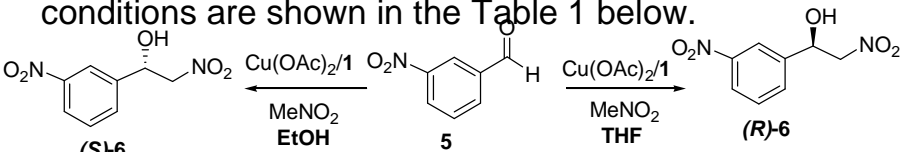

Scheme 2. Asymmetrical Henry reaction with $\left[\mathrm{Cu}(\mathrm{OAc})_{2} / 1\right]$.

\begin{tabular}{|c|c|c|c|c|c|}
\hline Entry & Solvent & $\begin{array}{c}\text { Time } \\
\text { (h) }\end{array}$ & Yield & e.e. ${ }^{b}$ & $\%$ cat. $^{a}$ \\
\hline 1 & THF & 120 & $81.4 \%$ & $26.8(\mathrm{R})$ & $5 \%$ \\
\hline 2 & THF & 120 & $78.5 \%$ & $27.3(\mathrm{R})$ & $10 \%$ \\
\hline 3 & THF & 120 & $71.4 \%$ & $22.7(\mathrm{R})$ & $20 \%$ \\
\hline 4 & THF & 120 & $81.2 \%$ & $26.1(\mathrm{R})$ & $30 \%$ \\
\hline 5 & $\mathrm{EtOH}$ & 120 & $98 \%$ & 13.3 (S) & $5 \%$ \\
\hline 6 & $\mathrm{EtOH}$ & 120 & $97.1 \%$ & 13.7 (S) & $10 \%$ \\
\hline 7 & $\mathrm{EtOH}$ & 120 & $97.3 \%$ & $15.9(\mathrm{~S})$ & $20 \%$ \\
\hline 8 & $\mathrm{EtOH}$ & 120 & $91.3 \%$ & $12.3(\mathrm{~S})$ & $30 \%$ \\
\hline & $\begin{array}{l}\text { The results } \\
(\%) \text { of cataly }\end{array}$ & 120 & rs) are s & own in table & 1. $\mathrm{mol}$ \\
\hline
\end{tabular}

Table 1. Nitro-aldol reaction using compound $\mathbf{1}$ as ligand

\section{CONCLUSION}

Using copper (II)/1 as a catalyst and ethanol as solvent asymmetrical nitro aldol reaction was performed in good yields although in lower enantiomeric excess. However, changing the solvent promoted an unexpected inversion ${ }^{[7]}$ in the configuration of product 6 . More experimental data are needed to elucidate this intriguing effect and to increase the enantiomeric excess.

\section{ACKNOWLEDGEMENTS}

CAPES, CNPq, FUNDAÇÃO ARAUCÁRIA e UFPR

\section{REFERENCES}

[1] Yuan, H., Hu, J., Gong, Y., Tetrahedron: Asymmetry, 2013, 24, 699.

[2] Ebru Aydin, A., Applied Organometallic Chemistry, 2013, 27, 283.

[3] Zhou, Z.-M., Li, Z.-H., Hao, X.-Y., Zhang, J., Dong, X., Liu, Y.-Q., Sun,

W.-W., Cao, D., Wang, J.-L., Organic \& Biomolecular Chemistry, 2012, 10, 2113.

[4] Evans, D. A., Seidel, D., Rueping, M., Lan, H. W., Shaw, J. T., Downey,

C. W., Journal of the American Chemical Society, 2003, 125, 12692.

[5] Didier, D., Schulz, E., Tetrahedron: Asymmetry, 2013, 24, 769.

[6] Peisach, J.; Blumberg, W.E. Arch. Biochem. Biophys. 1974 165(2), 691.

[7] Batók, M., Chemical Reviews, 2009, 110, 1663. 